\title{
Determination of the Conformational
}

\section{Preference of Para-Aminobenzoic Acid on}

\section{Vanadium Pentoxide Surface: an XPS and}

\section{DFT Study}

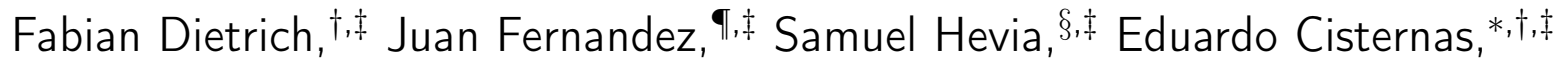
and Marcos Flores*,,$;$

$\dagger$ Physics Department, Universidad de La Frontera, Temuco, Chile $\ddagger$ Núcleo Milenio Multimat

\Laboratory of surfaces and nanomaterials, Physics Department, Universidad de Chile, Santiago, Chile

§Institute of Physics, Research Center for Nanotechnology and Advanced Materials (CIEN-UC), Pontificia Universidad Católica de Chile, Santiago, Chile.

E-mail: eduardo.cisternas@ufrontera.cl; mflorescarra@ing.uchile.cl 


\section{Supporting information for publication}
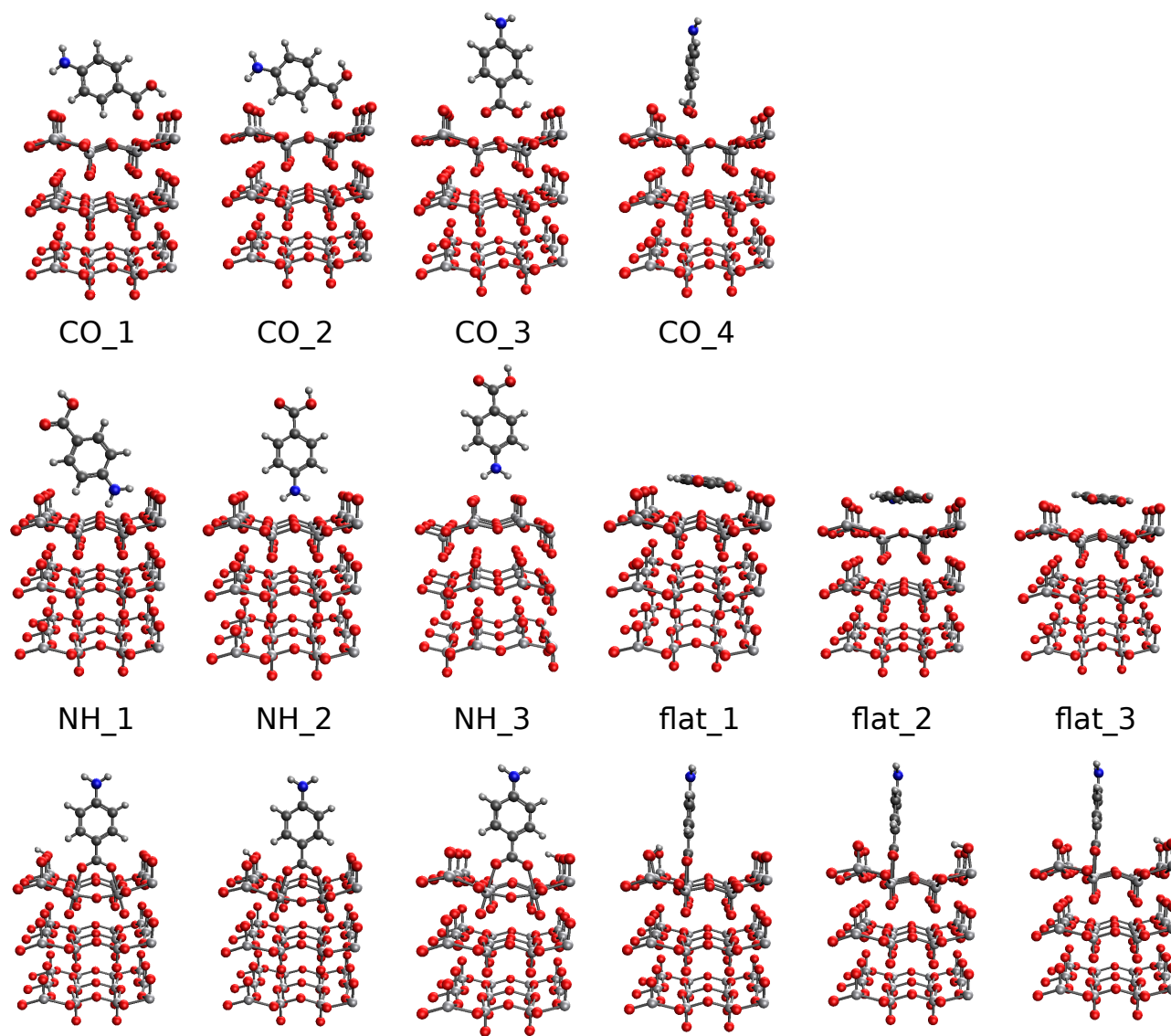

flat_1

$$
\text { flat_2 }
$$

flat_3

diss_1
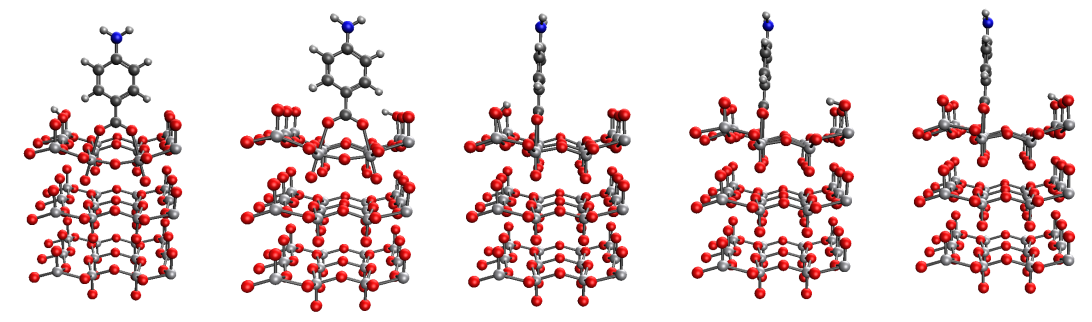

diss_3

diss_4

diss_5

diss_6

Figure S 1: Overview of all structures mentioned in Table 1. 

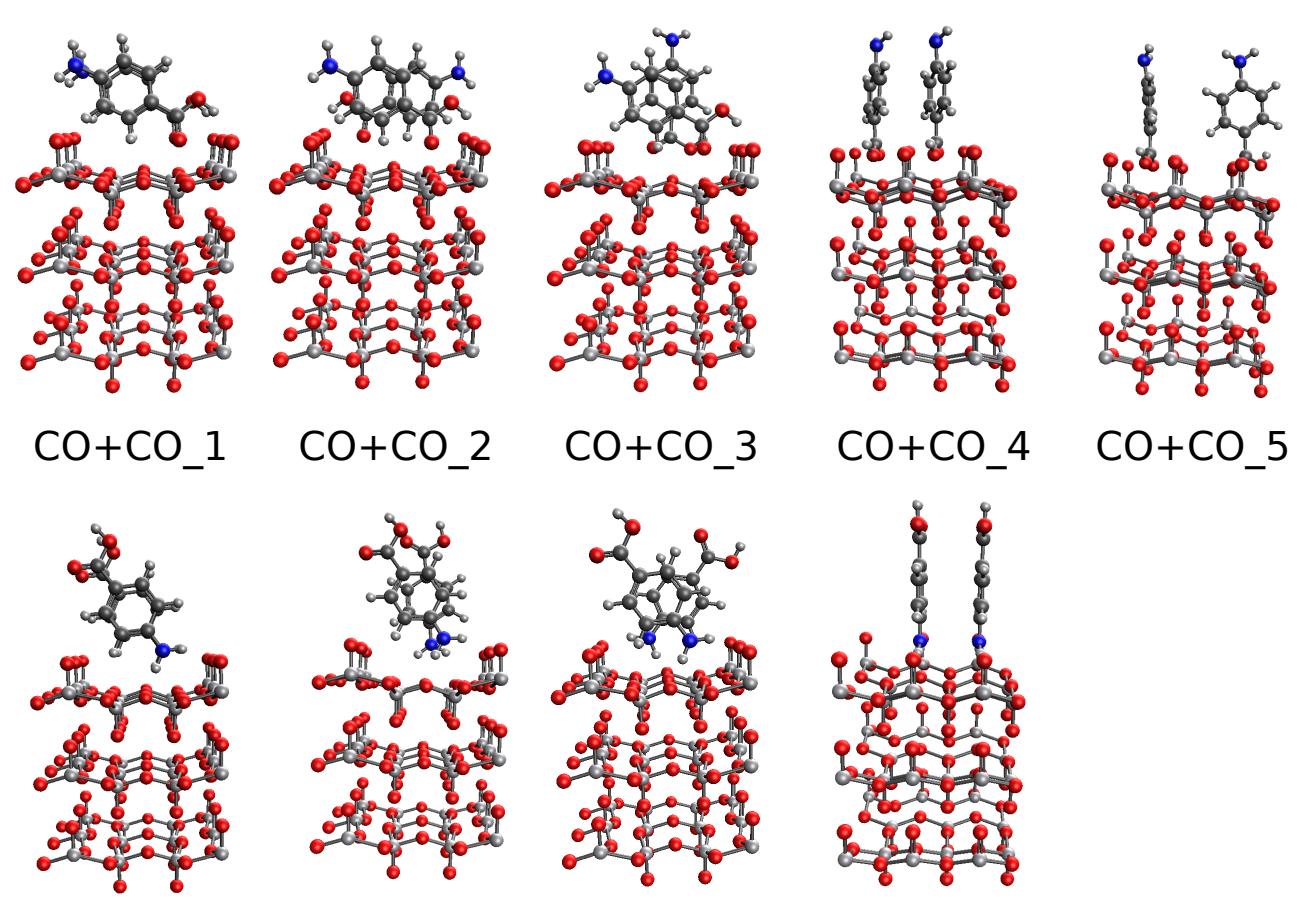

$\mathrm{NH}+\mathrm{NH} 1 \mathrm{NH}+\mathrm{NH}_{2} 2 \mathrm{NH}+\mathrm{NH} 3 \quad \mathrm{NH}+\mathrm{NH}_{4} 4$
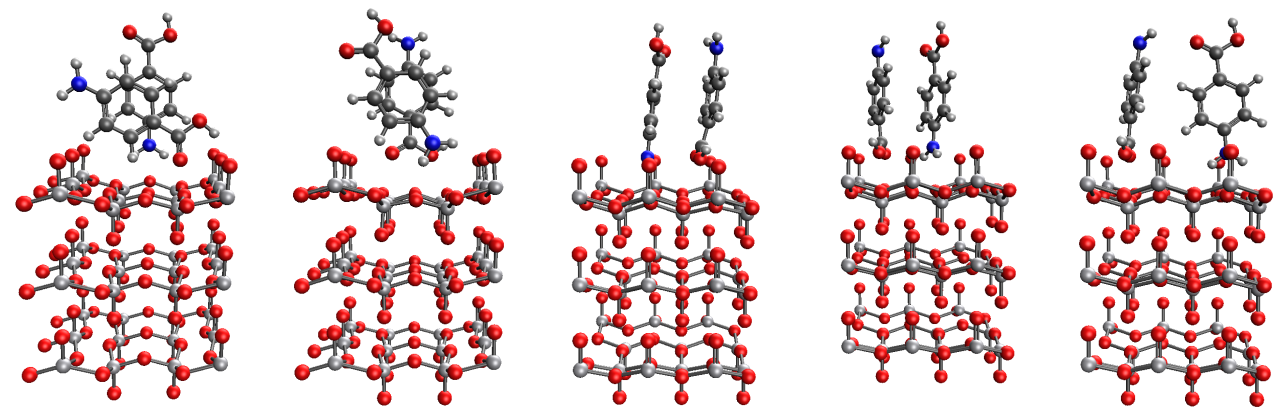

$\mathrm{CO}+\mathrm{NH}_{-} 1$

$\mathrm{CO}+\mathrm{NH}_{-} 2$

$\mathrm{CO}+\mathrm{NH}_{-} 3$

$\mathrm{CO}+\mathrm{NH}_{-} 4$

$\mathrm{CO}+\mathrm{NH}_{-} 5$
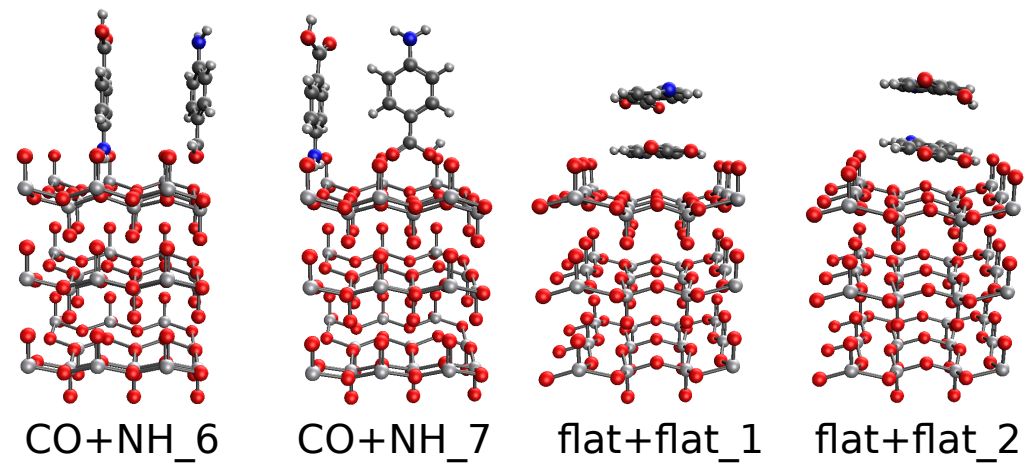

Figure S 2: Overview of all structures with two molecules mentioned in Table 2. 

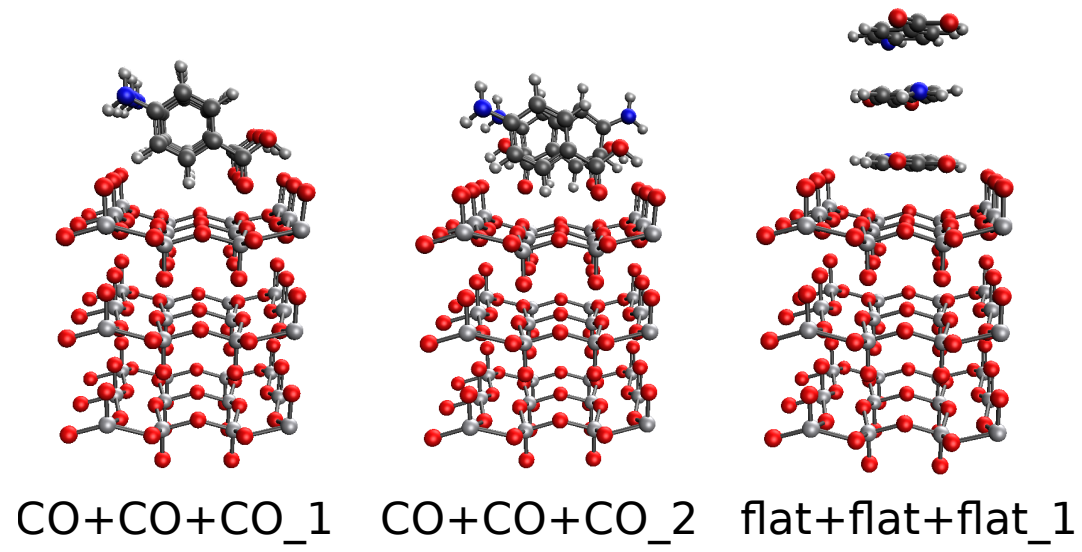

Figure S 3: Overview of all structures with three molecules mentioned in Table 2.

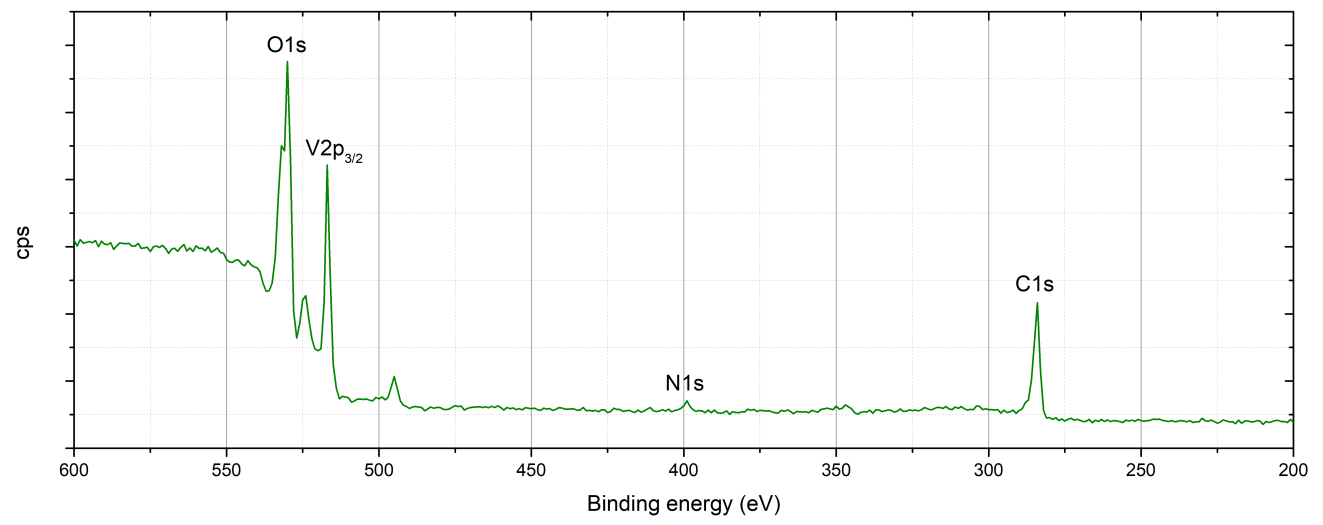

Figure S 4: Experimental XPS spectrum for a broad energy range. 

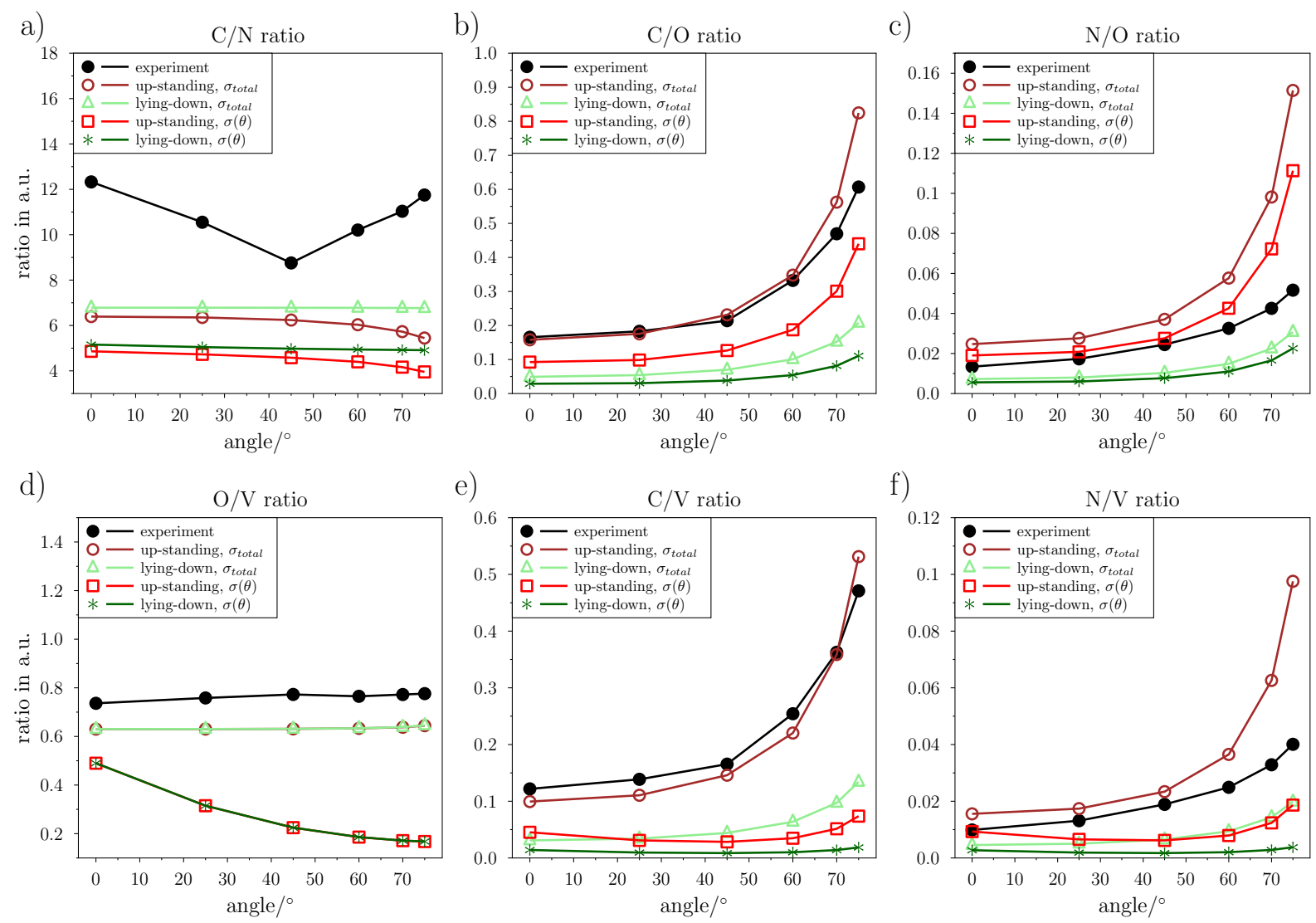

Figure S 5: Angular study of the ratio of atomic species detected on the PABA-SAMs $/ \mathrm{V}_{2} \mathrm{O}_{5}$ surfaces showing also the simulated values for the case that the cross section $\sigma$ is dependent on the angle $\theta$. 